$\overline{\text { Original }}$

\title{
Characterization and Protein Analysis of Escherichia coli Resistant to a Quaternary Ammonium Compound
}

\author{
TAKUYA MAEDA, SHINGO TANAKA, HIDEAKI NAGAMUNE, \\ AND HIROKI KOURAI* \\ Department of Biological Science and Technology, Faculty of Engineering. The University of Tokushima, \\ Minamijosanjima-cho, Tokushima 770-8506, Japan
}

Received 11 January 2005/Accepted 28 April 2005

\begin{abstract}
A resistant strain of Escherichia coli IFO12713, resistant against the quaternary ammonium compound (QAC), N-dodecylpyridinium iodide (P-12), was developed by using a standard broth dilution method and physiologically characterized by comparison to a sensitive strain. The cell surface hydrophobicity cultivated in the resistance-acquiring process gradually decreased and the lipopolysaccharides in the outer membrane increased. This result indicated that the cell surface of the resistant strain was more hydrophobic than that of the sensitive strain. One of the resistant strains isolated from the process also had resistance to other antibiotics and organic solvents. Rapid ethidium efflux was observed in the resistant strain compared to the sensitive strain. To elucidate the mechanism of resistance on a molecular level, protein analysis was performed with 2D-PAGE for the entire cellular fraction, and SDS-PAGE for the outer or inner membrane fractions. It was seen that 18 spots and bands of proteins specifically increased in the resistant strain. From the physiological characterization and the protein analysis, it was suggested that the QAC-resistant strain acquired its resistance by responding to antimicrobial stresses, stabilizing the outer membrane to control the adsorption/ binding reaction between the cell and agent, and activating the efflux pump against the antimicrobial agents.
\end{abstract}

Key words : Quaternary ammonium compound/Escherichia coli/Biocide resistance/Cell surface hydrophobicity/Efflux pump/Stress response.

\section{INTRODUCTION}

In the modern world, we have various techniques of microbial control to solve the problems caused by harmful microbes which contribute to food poisoning, hospital infections, microbial deterioration and so on. Among these techniques, the development and use of antimicrobial agents is one of the most important. Since there are numerous kinds of antimicrobial agents, the use of a suitable agent in the right way based on its antimicrobial potentiality or chemical and physical characteristics is necessary. Quaternary ammonium compounds (QACs), cationic surfactants,

*Corresponding author. Tel: +81-88-656-7408, Fax: +8188-656-9148. have been widely utilized for medical, industrial and domestic use because of their low toxicity or wide antimicrobial spectrum (Baley et al., 1977; Merianos, 2001). However, their utilization has brought about environmental pollution, harmful effects on humans and the growth of resistant bacteria. Therefore, it is necessary to elucidate the resistance mechanism of bacteria and development of novel biocides which do not produce resistant bacteria.

There are many reports about bacteria resistant to QACs, i. e., Escherichia coli, Klebsiella pneumoniae, Listeria monocytogenes, Pseudomonas aeruginosa, Staphylococcus spp., etc. (Aase et al., 2000; Alekshun and Levy, 2000; Heir et al., 1995; Ishikawa et al., 2002a and 2002b; Sakagami et al., 1989; Tabata et al., 2002, 2003a and 2003b). Generally, it is important to take measures against the emergence 
of Gram-negative bacteria, which are resistant to biocides or antiseptics in nature due to their cell surface structure, compared with Gram-positive bacteria (Denyer and Maillard, 2002). Major mechanisms of bacterial resistance to antimicrobial agents are known as 1) impermeability, 2) efflux, 3) modification of the target site, and 4) drug inactivation (Poole, 2002). Among them, possible ways to resist biocides involve impermeability and efflux (Russell, 2001). It is known that impermeability is due to the cell surface structure, particularly, the lipopolysaccharides of Gram-negative bacteria (Sukupolvi and Vaara, 1989). Drug efflux systems which consist of membrane proteins are called efflux pumps.

In this paper, we studied the characteristics of an $E$. coli strain resistant to a QAC, analyzed the cellular proteins, and investigated the mechanism of resistance.

\section{MATERIALS AND METHOD}

\section{Chemicals}

As a typical mono-QAC, $N$-dodecylpyridinium iodide (P-12) (Kourai et al., 1980) was synthesized in our laboratory. Benzalkonium chloride was obtained from Kanto Chemical Co., Inc. (Tokyo). Cetylpyridinium chloride was supplied by Tokyo Kasei Kogyo Co., Ltd. (Tokyo). TEGO-51 was purchased from Alfresa Pharma Corp. (Osaka). Methicillin, erythromycin, lincomycin, doxycycline and chloramphenicol were obtained from Sigma-Aldrich Corp. (St. Louis, MO, USA). Penicillin G, streptomycin, kanamycin and tetracycline were supplied by Wako Pure Chemical Industries, Ltd. (Osaka). All other chemicals were purchased from known suppliers and used without further purification.

\section{Organism and culture conditions}

The bacterial strain used for the experiment was $E$. coli IFO12713. It was cultured according to a previous report (Maeda et al., 1996).

\section{Measurement of antimicrobial activity}

The minimum inhibitory concentration (MIC) of the biocides was basically estimated according to the standard broth dilution method (Maeda et al., 1996).

\section{Development of $E$. coli with adapted resistance to P-12}

The adaptation of E. coli to QAC was basically carried out according to a previous report (Tabata et al., 2002).

\section{Estimation of organic solvent resistance}

The organic solvent resistance of $E$. coli was estimated according to a previous report (Aono and Kobayashi, 1997). Stationary phase cells ( $10^{7}$ cells) were plated on LBGMg agar (1\% tryptone, 0.5\% yeast extract, $1 \% \mathrm{NaCl}, 0.1 \%$ glucose, $10 \mathrm{mM} \mathrm{MgS}$ $\mathrm{O}_{4}, 1.5 \%$ agar, $\left.\mathrm{pH} 7.0\right)$ overlaid with $n$-hexane $(\varepsilon=$ 1.89), cyclohexane $(\varepsilon=2.05)$, toluene $(\varepsilon=2.24)$ and $p$-xylene $(\varepsilon=2.27)$. The parameter, $\varepsilon$, is the permittivity of the solvent (Asahara et al., 1976). The permittivity represents the affinity to the polar liquid, i. e., hydrophobicity. After incubation for $24 \mathrm{~h}$ at $37^{\circ} \mathrm{C}$, the growth of $E$. coli was estimated by visual inspection.

\section{Measurement of cell surface hydrophobicity}

The measurement of cell surface hydrophobicity and calculation of the hydrophobicity index $(\log \mathrm{HI})$ were basically performed according to a previous report (Kourai et al., 1989).

\section{Measurement of the amount of lipopoly- saccharides}

The measurement of the amount of lipopolysaccharides (LPS) on the cell surface was performed according to a previous report (Kourai et al., 1994).

\section{Measurement of efflux activity}

The measurement of the efflux activity was done according to a previous report (Masaoka et al., 2000). The E. coli cells were harvested at the late exponential phase, washed twice with M9 minimal medium and suspended in the same medium to an optical density of 0.2 at $660 \mathrm{~nm}$. Carbonylcyanide $\mathrm{m}$ chlorophenylhydrazone $(40 \mu \mathrm{M})$ and ethidium bromide $(2.5 \mu \mathrm{M})$ were added to the cell suspension. The cell suspension was incubated for $1 \mathrm{~h}$ at $37^{\circ} \mathrm{C}$ to deplete the energy of cells and to load the cells with ethidium. Then, cells were harvested and washed twice with the minimal medium supplemented with ethidium bromide (2.5 $\mu \mathrm{M}$, final concentration) and resuspended in the same medium to an optical density of 0.1 at $660 \mathrm{~nm}$. The cell suspension was preincubated at $37^{\circ} \mathrm{C}$ for $5 \mathrm{~min}$, and the assay was started. The fluorescence intensity of the assay mixture was measured at the excitation and emission wavelengths of 500 and $580 \mathrm{~nm}$, respectively, using the fluorescence spectrophotometer (F-3010, Hitachi Co., Ltd., Tokyo).

\section{Analysis of proteins}

The outer membrane fraction was prepared by the method of Nakajima et al., (1998). The cells of the resistant strain and the sensitive strain were cultured in nutrient broth containing P-12 (60 ppm, half of MIC) 
and fresh nutrient broth, respectively. Both of them were harvested at the late exponential phase. The outer membrane protein profile was analyzed by SDS-polyacrylamide gel electrophoresis (PAGE) (Laemmli, 1970) and two-dimensional PAGE (2DPAGE) in an electrophoresis apparatus (TEP-2, Shimadzu Co., Ltd., Kyoto). The electrophoresed gels were stained with silver nitrate. Sequencing of the amino acid sequences of the outer membrane proteins extracted from the acrylamide gel fragments from 2D-PAGE was carried out by a protein sequencer (PPSQ-10, Shimadzu Co., Ltd., Kyoto). Homology analysis of the amino acid sequences was performed with the protein database search programs, BLAST (http://blast.genome.jp/) and FASTA (http://fasta.genome.jp/). The isoelectric point of predicted proteins was calculated from the amino acid composition with a genetic information analyzing computer application (GENETYX, Software Development Co., Ltd., Tokyo).

\section{RESULTS AND DISCUSSION}

\section{E. coli with adapted resistance to P-12}

The development of the adapted resistance of $E$. coli to P-12 is shown in Fig. 1. The MIC constantly increased and reached the maximum of $120 \mathrm{ppm}$ (about 4-fold higher than MIC for the wild strain) after the eighth adaptation cycle. Therefore, it was shown that $E$. coli acquired a resistance to P-12 through repetition of the adaptation cycle. Since the MIC values did not change using the adapted bacterial strain recultured in fresh medium, the adapted resistance to $\mathrm{P}-12$ was proved to be stable. In the adaptation process, there are various strains of different sensitivity to

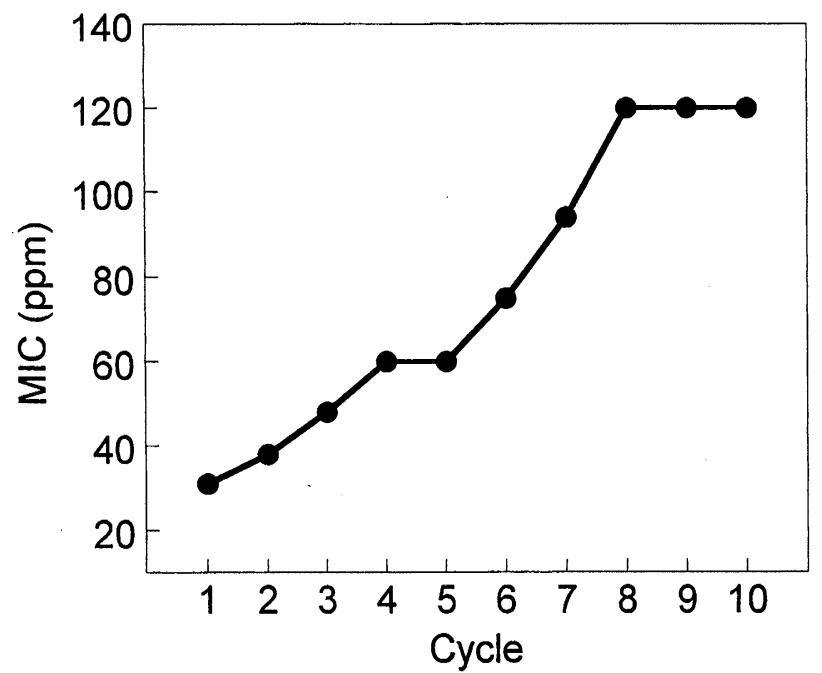

FIG. 1. Relationship between the adaptation cycle and MICs of P-12 for E. coli.
TABLE 1. MICs of various antimicrobial agents against the E. coli IFO12713 sensitive strain and resistant strain.

\begin{tabular}{lccc}
\hline \multirow{2}{*}{ Antimicrobial agents } & \multicolumn{3}{c}{ MIC (ppm) } \\
\cline { 2 - 4 } & Sensitive & Resistant & Fold \\
\hline Benzalkonium chloride & 3.9 & 7.8 & 2.0 \\
Cetylpyridinium chloride & 5.9 & 15 & 2.5 \\
TEGO-51 & 7.8 & 16 & 2.1 \\
Penicillin G & 24 & 150 & 6.3 \\
Methicillin & 900 & 5400 & 6.0 \\
Erythromycin & 370 & 750 & 2.0 \\
Lincomycin & 760 & 2900 & 3.8 \\
Streptomycin & 0.47 & 0.58 & 1.2 \\
Kanamycin & 0.14 & 0.27 & 1.9 \\
Tetracycline & 1.4 & 2.8 & 2.0 \\
Doxycycline & 3.9 & 6.2 & 1.6 \\
Chloramphenicol & 4.6 & 7.1 & 1.5 \\
\hline
\end{tabular}

$\mathrm{P}-12$. Then, the strain able to grow in the presence of $120 \mathrm{ppm}$ of P-12 was isolated from the culture at the tenth cycle, and the isolate was used for the experiment as the resistant strain. Specially for the analysis of cell surface hydrophobicity and LPS, the cultures of each adaptation cycle were used in order to investigate the typical characteristics of the various strains in the culture.

\section{MICs of various antimicrobial agents}

The MICs of various antimicrobial agents were measured. The resistant strain was more resistant than the sensitive strain to certain antibiotics, i. e., penicillin G, methicillin, erythromycin, lincomycin, streptomycin, kanamycin, tetracycline, doxycycline and chloramphenicol (Table 1). Those antibiotics have different sites of inhibition or modes of action. To benzalkonium chloride and cetylpyridinium chloride as cationic surfactants, and TEGO-51 as a zwitterionic surfactant, the resistant strain was more resistant than the sensitive strain. Thus it is suggested that the resistance to P-12 is not due to modification of the target sites or inactivation of the antibiotic but other mechanisms, i. e., decreased permeability or activated efflux.

\section{Organic solvent resistance}

The organic solvent resistance of the QACresistant strain was investigated (Fig. 2). The resistant strain was able to grow well in $n$-hexane while the sensitive strain grew little. In cyclohexane, the resistant strain grew well, but the sensitive strain did not, and both of the strains did not grow in toluene and $p$-xylene (data not shown). Therefore, the resistant strain was tolerant to relatively hydrophobic solvents, compared with the sensitive one. Since the organic solvent resistance is due to the barrier of the cell surface structure or activation of the efflux pump, the 

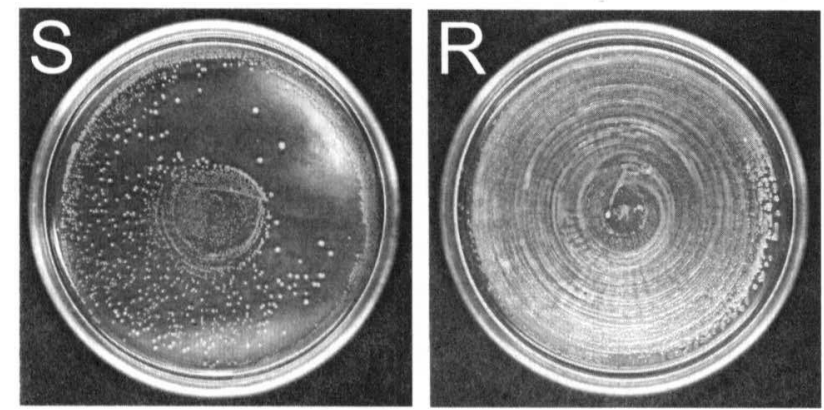

FIG. 2. Organic solvent resistance of E. coli IFO12713 sensitive strain (S) and resistant strain (R). The tested organic solvent was $n$-hexane.

result mentioned above may have relevance to the antibiotic resistance in Table 1.

\section{Cell surface hydrophobicity and lipopoly- saccharide}

Since the alteration of the hydrophobic interaction was important for the resistance to P-12 (Tabata et al., 2003a), the change in the cell surface hydrophobicity in the resistance-acquiring process was investigated (Fig. 3). Cell surface hydrophobicity gradually decreased in the process, and the surface hydrophobicity of the resistant strains was more hydrophilic than that of the sensitive strains. As the factor most likely affecting the cell surface hydrophobicity is thought to be the LPS (Denyer and Maillard, 2002), the amount of LPS was measured. The amount of LPS of the outer membrane increased with the decreasing hydrophobicity in the resistanceacquiring process (Fig. 4). LPS consists of a hydrophobic lipid and hydrophilic polysaccharides, and is a component of the outer membrane of gram-negative

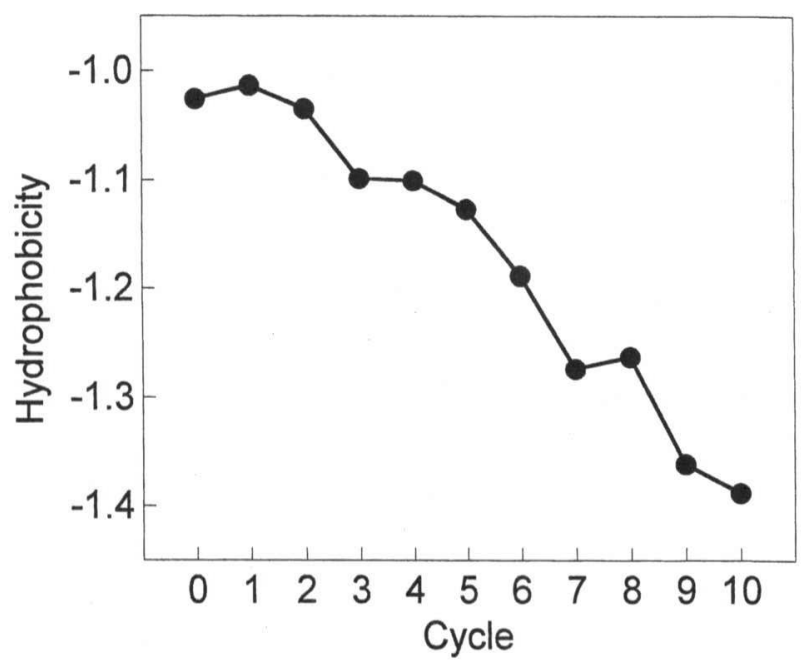

FIG. 3. Relationship between the adaptation cycle and cell surface hydrophobicity of $E$. coli.

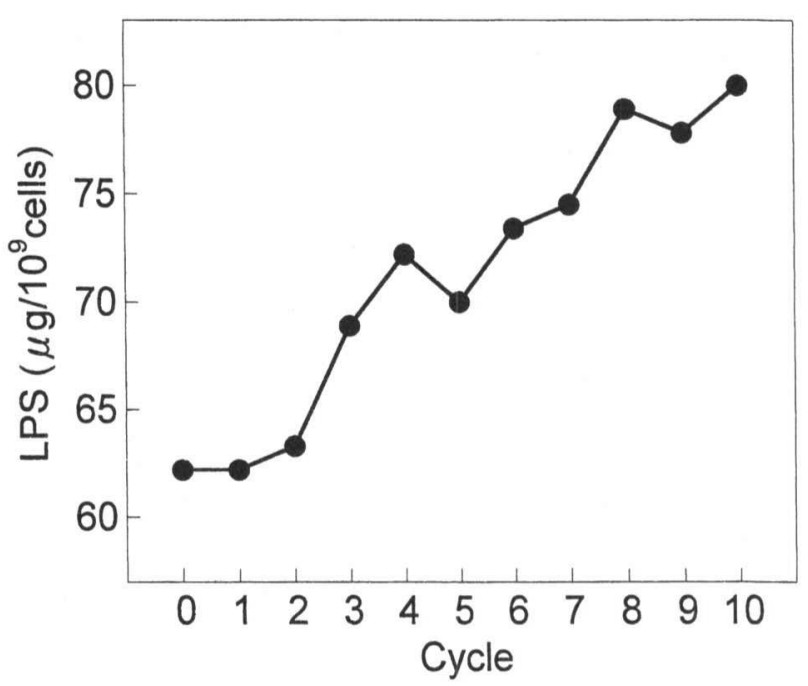

FIG. 4. Relationship between the adaptation cycle and the amounts of LPS of E. coli.

bacteria (Sukupolvi and Vaara, 1989). The hydrophilic characteristics of the resistant strain may be due to the extension of the polysaccharide chain or an increase in the amount of LPS. In any case, it seems that the change in the LPS obstructs the contact of P-12 to the bacterial surfaces.

In Fig. 1, the MIC reached the ceiling at eighth cycle, while the tendencies seen in Figs. 3 and 4 were different from it. If the mechanism of $\mathrm{P}-12$ resistance is exclusively caused by the change in cell surface hydrophobicity or LPS, such a phenomenon cannot be observed. Hence it is reasonable that there are resistance mechanisms other than the alteration of outer membrane.

\section{Efflux activity}

Based on the result mentioned above, it is suggested that multidrug efflux pumps are activated in the QAC-adapted E. coli. Ishikawa et al. (2002a) reported that EmrE, a typical small multidrug resistance (SMR) family multidrug efflux pump, increased the resistance to cetyltrimethylammonium bromide and benzalkonium chloride, popular cationic QACs. In another report (Masaoka et al., 2000), the ethidium efflux assay was used to estimate the activity of EbrAB which is a SMR family multidrug efflux pump. Therefore, to investigate the activation of multidrug efflux pumps in the QAC-adapted E. coli, the ethidium efflux was measured. Energy starved cells were first loaded with ethidium, and glucose was added to energize the cells. As shown in Fig. 5, a rapid ethidium efflux was observed with the resistant cells just after the addition of glucose. On the other hand, only a slow efflux of ethidium was observed with the normal cells. This result supports the idea that one of the 


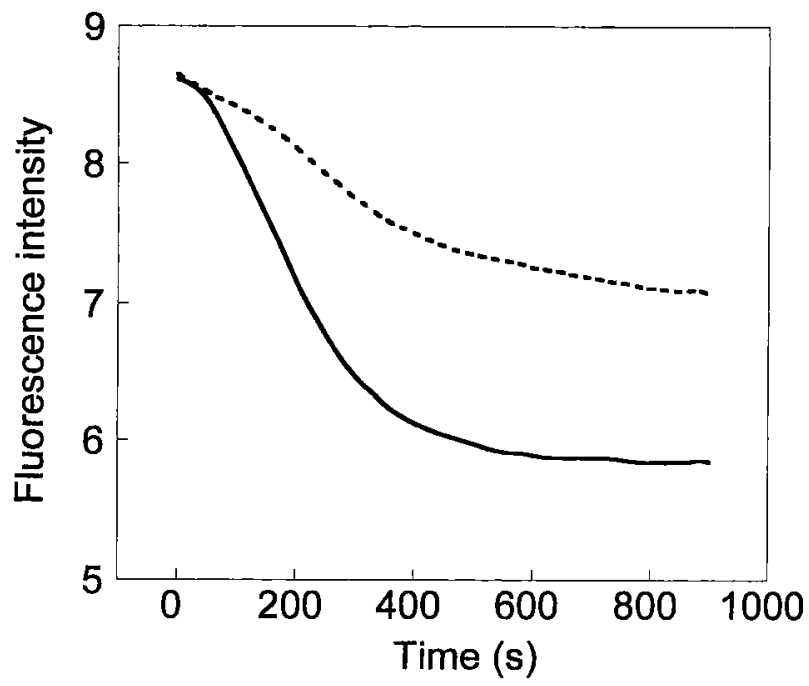

FIG. 5. Assay of ethidium efflux activity. The dashed and solid lines indicate the cellular ethidium accumulation in the $E$. coli sensitive strain and resistant strain, respectively.

resistant mechanisms of the QAC-adapted $E$. coli is an acceleration of the drug efflux.

\section{Protein analysis}

To investigate the resistance mechanism on a molecular level, a protein analysis was performed with 2D-PAGE for the entire cellular fraction (Fig. 6) and SDS-PAGE for the outer and inner membrane fractions (Figs. 7A and 7B). Consequently, the amounts of 18 spots and bands of proteins specifically increased in the resistant strain.

As for the entire cellular fraction, 9 proteins were identified (Table 2). Tryptophanase and isocitrate dehydrogenase are related to the TCA cycle, and the 6-phosphogluconate dehydrogenase to pentose-
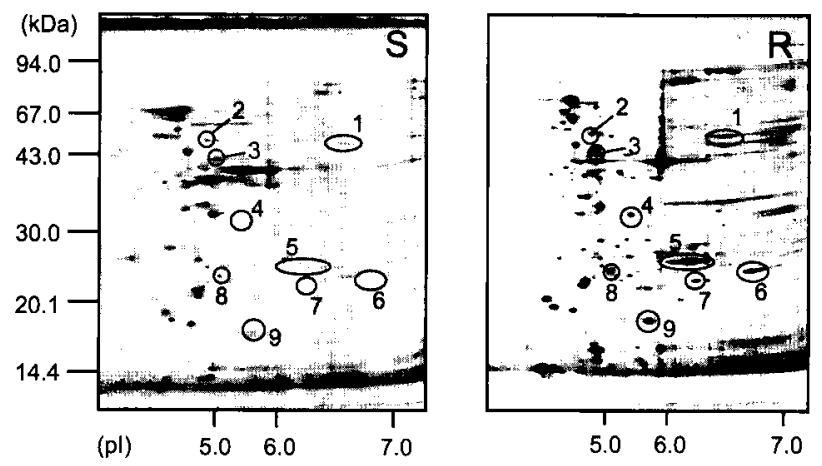

FIG. 6. 2D-PAGE analysis of the entire cellular proteins of the $E$. coli sensitive strain (S) and resistant strain (R). The amount of proteins loaded onto each gel was 100 $\mu \mathrm{g}$. The circles indicate the spots of proteins which specifically increased in the resistant strain. The numbers close to the circles correspond to those of Table 2.
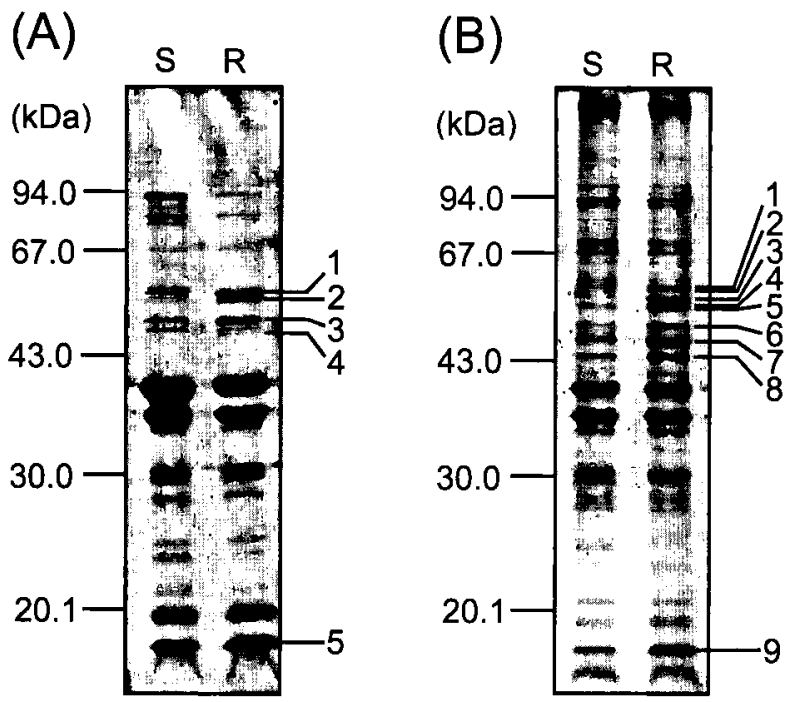

FIG. 7. SDS-PAGE analysis of the outer membrane proteins $(A)$ and the inner membrane proteins $(B)$ of $E$. coll sensitive strain (S) and resistant strain (R). The amount of proteins loaded onto each well was $10 \mu \mathrm{g}$. The bars indicate the bands of proteins which specifically increased in the resistant strain. The number of bars corresponds to those in Tables $3 \mathrm{~A}$ and $3 \mathrm{~B}$.

phosphate cycle, which functions to produce energy. Cytidine deaminase and adenine phosphoribosyl transferase are concerned with nucleic acid metabolism, and oxygen-insensitive $N A D(P) H$ nitroreductase with amino acid metabolism. Superoxide dismutase and peptidyl-prolyl cis-trans isomerase B are stress responding proteins. The function of the modulator of drug activity $B$ is unknown.

As for the outer and inner membrane fractions, 4 and 8 proteins were identified (Tables $3 \mathrm{~A}$ and $3 \mathrm{~B}$ ), respectively. The outer membrane protein TolC, maltoporin, and long chain fatty acid transport protein are porins, which play the role as an efflux pump. The function of the outer membrane protein $\mathrm{OmpX}$ is adhesion to mammalian cells. The aerobic glycerol-3phophate dehydrogenase, ATP synthase $\alpha$ chain and ATP synthase $\beta$ chain are related to energy production. The outer membrane protein TolB stabilizes the outer membrane. The D-alanyl-D-alanine carboxypeptidase fraction A functions during the synthesis of peptideglycan, which is a major component of the cell surface structure.

From the physiological characterization and the protein analysis, it was suggested that the QACresistant strain acquired its resistance by responding to antimicrobial stresses (superoxide dismutase and peptidyl-prolyl cis-trans isomerase B), stabilizing the outer membrane to control the adsorption/binding reaction between the cell and agent (OmpX and Dalanyl-D-alanine carboxypeptidase), and activating 
TABLE 2. Proteins identified by amino acid sequences from 2D-PAGE separation of resistant $E$. coli entire cellular fractions.

\begin{tabular}{|c|c|c|c|c|c|}
\hline Spot & Amino acid sequences & Name & Function & $\mathrm{Mw}(\mathrm{kDa})$ & $\mathrm{pl}$ \\
\hline 1 & MENFKHLPEPFR & TnaA & Tryptophanase (EC.4.1.99.1) & 52.8 & 5.85 \\
\hline 2 & $M E S K \vee \vee \vee P A Q G$ & Idh & Isocitrate dehydrogenase (EC.1.1.1.42) & 45.8 & 5.01 \\
\hline 3 & $S K Q Q \mid G \vee \vee G M A \vee$ & $6 \mathrm{Pgd}$ & 6-Phosphogluconate dehydrogenase (EC.1.1.1.44) & 51.5 & 4.90 \\
\hline 4 & M HPR $F$ Q TAFAQL & Cdd & Cytidine deaminase (EC.3.5.4.5) & 31.5 & 5.35 \\
\hline 5 & $M D \| S \vee A L K R H S$ & $\mathrm{NfnB}$ & Oxygen-insensitive NAD (P) H nitroreductase (EC.1.6.99.7) & 23.9 & 5.78 \\
\hline 6 & SYTLPSLPYAYD & SodM & Superoxide dismutase (EC.1.15.1.1) & 23.3 & 6.51 \\
\hline 7 & $S N|L| \mid N G A K$ & MdaB & Modulator of drug activity $B$ & 21.9 & 5.84 \\
\hline 8 & TA TAQQLEYLKN & Apt & Adenine phosphoribosyl transferase (EC.2.4.2.7) & 19.9 & 5.13 \\
\hline 9 & MVTFHTNHGDIV & PpiB & Peptidyl-prolyl cis-trans isomerase B (EC.5.2.1.8) & 18.2 & 5.43 \\
\hline
\end{tabular}

Name, function and molecular weight $(\mathrm{Mw})$ were obtained by homology analysis of the amino acid sequences, and the isoelectric point $(\mathrm{pl})$ was calculated from the amino acid composition of the predicted proteins.

TABLE 3A. Proteins identified by amino acid sequences from SDS-PAGE separation of resistant $E$. coli outer membrane fractions.

\begin{tabular}{|c|c|c|c|c|c|}
\hline Band & Amino acid sequences & Name & Function & $M w(k D a)$ & $\mathrm{pl}$ \\
\hline 1 & $E N L M Q \vee Y Q Q A R L$ & TolC & Outer membrane protein TolC & 54.0 & 5.34 \\
\hline 2 & $E N L M Q \vee Y Q Q A R L$ & TolC & Outer membrane protein TolC & 54.0 & 5.34 \\
\hline 3 & VDFHGYARSGIG & LamB & Maltoporin precursor & 49.9 & 4.66 \\
\hline 4 & $A G F Q L N E F S$ & FadL & Long-chain fatty acid transport protein & 48.8 & 5.06 \\
\hline 5 & A T S TVTGGYAQS & OmpX & Outer membrane protein OmpX & 18.7 & 7.11 \\
\hline
\end{tabular}

Name, function and molecular weight ( $\mathrm{Mw}$ ) were obtained by homology analysis of the amino acid sequences, and the isoelectric point $(\mathrm{pl})$ was calculated from the amino acid composition of the predicted proteins.

TABLE 3B. Proteins identified by amino acid sequences from SDS-PAGE separation of resistant $E$. coli inner membrane fractions.

\begin{tabular}{|c|c|c|c|c|c|}
\hline Band & Amino acid sequences & Name & Function & $\mathrm{Mw}(\mathrm{kDa})$ & $\mathrm{pl}$ \\
\hline 1 & METKDLIVIGV & GIpD & Aerobic glycerol-3-phophate dehydrogenase (EC.1.1.99.5) & 57.3 & 7.09 \\
\hline 2 & $M Q L N S T E \mid S E$ & AtpA & ATP synthase $\alpha$ chain (EC.3.6.3.14) & 55.3 & 5.74 \\
\hline 3 & $E N L M Q \vee Y Q Q A R L$ & TolC & Outer membrane protein TolC & 54.0 & 5.34 \\
\hline 4 & $E N L M Q \vee Y Q Q$ & TolC & Outer membrane protein TolC & 54.0 & 5.34 \\
\hline 5 & $A T G K \mid \vee Q \vee I$ & AtpB & ATP synthase $\beta$ chain (EC.3.6.1.34) & 50.2 & 4.76 \\
\hline 6 & VDFHGYARSG & LamB & Maltoporin precursor & 49.9 & 4.66 \\
\hline 7 & $E \vee R|\vee| D S G \vee$ & TolB & Outer membrane protein TolB & 46.0 & 7.72 \\
\hline 8 & $X X L N|K T M| P$ & DacA & D-Alanyl-D-alanine carboxypeptidase fraction A (EC.3.4.16.4) & 44.4 & 8.55 \\
\hline 9 & A T STVTGGYA & OmpX & Outer membrane protein OmpX & 18.6 & 7.11 \\
\hline
\end{tabular}

Name, function and molecular weight $(\mathrm{Mw}$ ) were obtained by homology analysis of the amino acid sequences, and the isoelectric point ( $\mathrm{pl}$ ) was calculated from the amino acid composition of the predicted proteins.

the efflux pump against antimicrobial agents (TolB, TolC and maltoporin). However, to elucidate the QAC-resistant mechanism in detail, it would be necessary to confirm the general tendency of the protein analysis data among resistant strains and to study the functions of those proteins in the resistant cell and the relation between them and the resistanceacquiring process.

\section{REFERENCES}

Aase, B., Sundheim, G., Langsrud, S., and Rørvik, L. M. (2000) Occurrence of and a possible mechanism for resistance to a quaternary ammonium compound in Listeria monocytogenes. Int. J. Food Microbiol., 62, 57-63.

Asahara, T., Tokura, N., Okawara, M., Kumanotani, J., and Senoo, M. (1976) Yozai Handbook (in Japanese), pp. 883, Kodansha Ltd., Tokyo.

Aono, R., and Kobayashi, H. (1997) Cell surface properties of organic solvent-tolerant mutants of Escherichia coli K12. Appl. Environ. Microbiol., 63, 3637-3642.

Alekshun, M. N., and Levy, S. B. (2000) Bacterial drug resistance: Response to survival threats. In Bacterial Stress Responses (Storz, G., and Aronis, R. H., ed.), pp. 323366, ASM Press, Washington D.C.

Baley, G. J., Peck, G. E., and Banker, G. S. (1977) Bactericidal properties of quaternary ammonium compounds in dispersed systems. J. Pharm. Sci., 66, 696699.

Denyer, S. P., and Maillard, J.-Y. (2002) Cellular 
impermeability and uptake of biocides and antibiotics in Gram-negative bacteria. J. Appl. Microbiol., 92, 35S-45S. Heir, E., Sundheim, G., Holck, A. L. (1995) Resistance to quaternary ammonium compounds in Staphylococcus spp. isolated from the food industry and nucleotide sequence of the resistance plasmid PST827. J. Appl. Bacteriol., 79, 149-156.

Ishikawa, S., Matsumura, Y., and Tsuchido, T. (2002a) Resistance to cationic surfactants and some other agents of Escherichia coli recombinants with an abundant number of genes encoding drug efflux pump. Biocontrol Sci., 7, 115-120.

Ishikawa, S. Matsumura, Y., Yoshizako, F., and Tsuchido, T. (2002b) Characterization of a cationic surfactantresistant mutant isolated spontaneously from Escherichia coli. J. Appl. Microbiol., 92, 261-268.

Kourai, H., Horie, T., Takeichi, K., and Shibasaki, I. (1980) The antimicrobial characteristics of quaternary ammonium salts and their alkyl chain length (in Japanese). J. Antibact. Antifung. Agents, 8, 191-199.

Kourai, H., Takechi, H., Muramatsu, K., and Shibasaki, I. (1989) Relationship between hydrophobicity of bacterial cell surface and drug-susceptibility to alkylpyridinium iodides. J. Antibact. Antifung. Agents, 17, 119-128.

Kourai, H., Oda, K., Takechi, H., and Nakagawa, K. (1994) The antimicrobial characteristics of poly [dimethyliminio (polymethylene) chloride]s. J. Antibact. Antifung. Agents, 22, 519-530.

Laemmli, U. K. (1970) Cleavage of structural proteins during the assembly of the head of bacteriophage T4. Nature, 227, 680-685.

Maeda, T., Goto, S., Manabe, Y., Okazaki, K., Nagamune, H., and Kourai, H. (1996) Bactericidal action of $N$ alkylcyanopyridinium bromides against Escherichia coli K12 W3110. Biocontrol Sci., 1, 41-49.

Masaoka, Y., Ueno, Y., Morita, Y., Kuroda, T., Mizushima, T., and Tsuchiya, T. (2000) A two-component multidrug efflux pump, EbrAB, in Bacillus subtilis. J. Bacteriol.,182,
2307-2310.

Merianos, J. J. (2001) Surface active agents. In Disinfection, sterilization and preservation (Block, S. S., ed.), pp.283-320, Lippincott Williams and Wilkins, Philadelphia.

Nakajima, A., Hoshikawa, M., and Nakae, T. (1998) Antibiotic stress induces a large amount of outer membrane protein in Pseudomonas aeruginosa. FEMS Microbiol. Lett., 15, 261-265.

Poole, K. (2002) Mechanism of bacterial biocide and antibiotic resistance. J. Appl. Microbiol., 92, 55S-64S.

Russell, A. D. (2001) Principles of antimicrobial activity and resistance. In Disinfection, sterilization and preservation (Block, S. S., ed.), pp.31-55, Lippincott Williams and Wilkins, Philadelphia.

Sakagami, Y., Yokoyama, H., Nishimura, H., Ose, Y., and Tashima, T. (1989) Mechanism of resistance to benzalkonium chloride by Pseudomonas aeruginosa. Appl. Environ. Microbiol., 55, 2036-2040.

Sukupolvi, S., and Vaara, M. (1989) Salmonella typhimurium and Escherichia coli mutants with increased outer membrane permeability to hydrophobic compounds. Biochim. Biophis. Acta, 988, 377-387.

Tabata, A., Maeda, T., Nagamune, H., and Kourai, $H$. (2002) Characterization of Pseudomonas aeruginosa resistant to a quaternary ammonium compound. Biocontrol Sci., 7, 147-153.

Tabata, A., Maeda, T., Nagamune, $H_{\text {., }}$ and Kourai, $H$. (2003a) The properties of bacterial adaptation to monoand bis-quaternary ammonium compounds. Biocontrol Sci., 8, 37-42.

Tabata, A., Nagamune, H., Maeda, T., Murakami, K., Miyake, Y., and Kourai, H. (2003b) Correlation between resistance of Pseudomonas aeruginosa to quaternary ammonium compounds and expression of outer membrane protein OprR. Antimicrob. Agents Chemother., 47, 2093-2099. 